THURSDAY, JANUARY 3, I9OI.

\section{THE NEW CENTURY.}

C CIENCE is cosmopolitan. Electricity abolishes time and envelops both hemispheres with a new idea as soon as it has emerged from the brain of the Thinker. Mechanics, by its space-annihilating power, has reduced the surface of the planet to such an extent that the human race now possesses the advantage of divelling, as it were, on a tiny satellite. Both these agencies, then, combine to facilitate a rapid exchange of new ideas and commodities, as well as of those who are interested in them in whatever capacity.

These considerations indicate some of the most momentous changes which have occurred in the world's history since the last century dawned.

How have they been brought about? M. Maurice Lévy, in one of those allocations-always so admirable in thought and style-pronounced by the President of the French Academy of Sciences at the annual public meeting held each December, answered the question for us last month.

"Let us never forget that if applied mechanics has arrived to-day at such marvellous results, if we can now calculate beforehand the parts of the most complex machines, it is because long ago the shepherds of Chaldea and Judea observed the stars; because Hipparchus combined their observations with his own and handed them down to us; because Tycho-Brahe made better ones; because two thousand years ago a great geometer, Appolonius of Perga, wrote a treatise on conic sections, regarded for many centuries as useless; because the genius of Kepler, utilising this admirable work and the observations of Tycho-Brahe, gave us those sublime laws which themselves have been considered useless by the utilitarians; and, finally, because Newton discovered the law of universal gravitation."

From this discovery of Newton, M. Lévy points out, first came the study of Celestial Mechanics, from which was derived later General Mechanics, from which again, later still, Industrial Mechanics, which are now applied every day, has taken its origin. He adds :

"It is well to impress the fact that Industrial Mechanics has come down from heaven, upon the utilitarians; upon those who appreciate science only so far as it can be immediately profitable to them; who are always complaining that too much is taught at school, and who regard as superfluous everything they cannot find in a formulary, manual or aid to memory."

All our progress, then, if we accept the view to which M. Maurice Lévy has given expression, has corne from the study of what was useless at the time it was studied. There is no doubt that this view is correct, and that future developments, probably as momentous as those to which we have already referred, will in the future come to us from the same source.

To study the useless, therefore, is as important as to apply the useful, from a cosmopolitan point of view ; and all wise governments and institutions should use their most strenuous efforts to aid the first endeavour, the second can very well take care of itself.

NO. 1627 , vOL. 63]
There can be no question that the progress of science and of the applications of science to industry will go on in a geometrical ratio, and that eventually every country will benefit by this advance ; but if we quit the cosmopolitan point of view and endeavour to form an idea of the results of this advance on any country in particular, another set of considerations comes in.

Our Empire, as it exists at present, and our great national wealth, are the results of the sea-training and prowess of her sons and of the stores of natural wealth in the shape of coal and iron which the first appliers of mechanics found to their hand. The output and first user of coal and iron depended upon the applications of mechanics, and the first user of all these combined enabled us to flood the markets of the world, and for years Britain was the Tubal Cain among the nations. Not only had we a monopoly of export, but so high an authority as Sir Andrew Noble acknowledges that, fifty years ago, British machinery was immeasurably superior to any other. But even this statement does not exhaust all our then advantages. Because we were the great producers we became the great carriers of the world; hence the supremacy of our mercantile marine, and, flowing from this, our command of the sea. At that time Germany did not exist as a united nation, France was mainly agricultural, and the United States were engaged in developing their enormous and almost unpopulated territories.

But what has happened since? As we have said, science is cosmopolitan, and the levelling effect of this has been that the material advantages we possessed in the first instance have disappeared. Other countries, chiefly those we have named, have now their coal and iron and applications of science as well as ourselves.

First among these applications at the beginning of the last century came steam locomotion, the gift to the world of a former "instrument maker to the University of Glasgow," and from the work done on the Forth and Clyde Canal in 1802 have sprung all the navies and railways of the world.

For traction purposes steam is now giving way to electricity; but how different is the rôle that Britain is playing at the beginning of the new century compared with that she filled at the beginning of the old one. We import instead of exporting. The chief London electric railway is American, American coal is producing gas to light the streets of the Metropolis, American cars are now found on our English trains, which on some lines are drawn by American locomotives. British applications to facilitate locomotion, therefore, have ceased to be paramount, and at the same time we no longer occupy the proud position of being the only nation of shopkeepers.

Were this all, it would be abundantly clear that our old supremacy must cease, and from no fault of our own, as it is but a direct consequence of the general progress of science, which includes the facilitating of intercommunications. But, unfortunately, it is not all.

At a time when our ancient universities occupied no higher level than that, according to Matthew Arnold, of " hauts Lycées," and when there was little or no attempt at 
educating the large majority of the population, Prussia, which, with the rest of the German States, had profited by Luther's appeal in favour of the education of the people, h ad occupied herself, crushed though she was after Jena, with the founding of universities and with the highest education; while live seats of learning in great numbers were being founded in the United States. The beginning of the new century, then, finds us in a position which every day differs more and more from that occupied by us in the old one, for not only are our natural resources relatively reduced in value, but our intellectual resources are not sufficiently superior to those of other nations to enable us to retain our old position by force of brains.

But even this statement does not truly paint the situation. From time to time since this journal was started in 1869 , it has been our duty to insist upon our relative deficiencies in regard to the advancement of science and the higher scientific instruction. Thus, in the very first volume of NATURE, the absence here of the great facilities and encouragement given in Germany to these matters was clearly indicated. As an early instance of the result of this state of things we may refer to $\mathrm{Mr}$. Perkin's account, in $1885,{ }^{1}$ of the migration of the coaltar industry to Germany. In later years ample proof has been adduced that in many directions the present British intellectual equipment is not only not superior, but actually inferior to that of other countries, and none too soon the matter is engaging attention in the daily press. Within the last week the Times, Daily Mail and Pall Mall Gazette have called special attention to the reasons which may be assigned for this new and alarming state of things; a writer in the Fortnightly has gone so far as to ask, "Will England last the Century?" while Sir Henry Roscoe has expressed his opinions in a letter to the Times as follows :-

"There can be no manner of doubt that a crisis in our national well-being has already been reached. The news brought to us from all quarters proves that our industrial and commercial prosperity is being rapidly undermined. The cry that we are being outbid on all sides by Germany and America is no new one, but it becomes louder and louder every day, and now it is admitted by all those best qualified to judge that, unless some drastic steps are taken to strengthen our educational position in the direction long ago taken up by our competitors, we stand to lose, not merely our industrial supremacy, but the bulk of our foreign trade. . . . The only policy at this time is to strain every nerve to place the country educationally on a level with its neighbours. No effort, no expenditure, is too great to secure this result, and unless our leaders, both in statecraft and in industry, are quickly aroused to the critical condition of our national affairs in this respect, and determine at once to set our house in order, our children and grandchildren may see England sink to the level of a third-rate Power; for upon education, the basis of industry and commerce, the greatness of our country depends."

We must confess that when we come to consider the panaceas suggested by these writers we find much more vagueness than might be expected, and some suggestions which are entirely beside the mark.

Thus we are told that now our Colonies are being more closely united to us we may rest and be thankful ; that

I NATURE, vol. xxxii. p. 343.

No. $x 627$, voL. 63$]$
American industry depends for its success upon the extreme youth of those who are at the head of affairs. Education is referred to as if there were no differences in the methods employed, and finally a newly-developed sloth is suggested as the origin of the apparent decadence of the most athletic nation in the world.

The question arises, Is there no scientific method open to us to get at the real origin of the causes which have produced the present anxiety?

M. Maurice Lévy, in his allocation, did England the honour to point out how large a share Newton had in founding the industries on which our commercial greatness in the last century was based. It seems to us to be our duty, at the beginning of the new century, to suggest that at this critical time it would be criminal to neglect the labours of another great EnglishmanDarwin - which may be appealed to to help us to see what has gone wrong and to forecast what the future has in store for us if we apply the suggested remedies or if we neglect them. In this we possess an advantage over our forerunners. Those labours have shown the working of an inexorable law which applies exactly to the conditions under which we find ourselves.

The enormous and unprecedented progress in science during the last century has brought about a perfectly new state of things, in which the "struggle for existence" which Darwin studied in relation to organic forms is now seen, for the first time, to apply to organised communities, not when at war with each other, but when engaged in peaceful commercial strife. It is a struggle in which the fittest to survive is no longer indicated by his valour and muscle and powers of endurance, but by those qualities in which the most successful differs most from the rest. We must accept the conclusion that, with material outfits now much more equally distributed for this struggle for existence, if Britain be at a disadvantage in relation to any other nation with regard to these qualities, it must go under if such a condition of things is allowed to go on. If this appeal to a natural law leads to such a dire conclusion, it is the duty of every Briton, from the highest to the lowest, to see to it that some efficient remedy be applied without delay.

It follows from what has already been stated that we need not look for these national differences among natural products for the reason that, day by day, such differences are being levelled by the present ease and rapidity of intercommunication.

We do not think that the differences will be found in any very great degree in our primary and technical instruction as it is going on to-day.

If we regard our primary, secondary and higher education, it must be acknowledged that great improvements have been carried out during the last quarter of a century. The establishment of new universities, adapted to the present conditions of civilisation, in several great centres and the promise of more, has clearly shown that, in the opinion of our most important mercantile coinmunities, strong measures are necessary, and that they are prepared to make great pecuniary sacrifices to carry them out. Still, the facts show that what has already been done 
is not sufficient, and that we must do more in these directions; but the present difference in these respects is not entirely sufficient to account for the present condition of things.

Continuing our process of exclusion we finally arrive at the possibility that the present superiority of our competitors depends as much upon Liebig's introduction of practical scientific work and research into the general higher education as did our former supremacy upon Watt's introduction of the steam engine. Voltaire said, "On étudie les livres en attendant qu'on étudie les hommes." The proper study of Science gives us a third term, the study of things and laws in action; a study in which the eye and hand and brain must work together to produce the scientific spirit or properly organised common sense.

The Scientific spirit existed among our European competitors much more generally than it did with us long before Liebig, and it was utilised over a far wider field of knowledge ; but from Liebig's time it has existed among them as the dominant factor in Industry and Commerce, and the closer union between Science and Industry in other countries is, we believe, the true origin of the present difference between them and our own.

Here, we tried to start chemical industries by employ. ing chemists, as Mr. Perkin has told us, at "bricklayers' wages." In Germany they are now carried on by scores, in one case a hundred, of the best trained chemists the country can produce, in research laboratories attached to all the great works. At this moment German artificial indigo threatens to replace the natural product in all the markets of the world as a result of these scientific industrial methods. So soon as Science was acknowledged to be the most important commercial factor, the Reichsanstalt was established by the Government at a cost of $200,000 /$., and a yearly expenditure of $15,000 /$. to weld science and industry more closely together. An American professor thus summarises the results :

"The results have already justified, in a remarkable manner, all the expenditure of labour and money. The renown in exact scientific measurements formerly possessed by France and England has now largely been transferred to Germany. Formerly scientific workers in the United,States looked to England for exact standards, especially in the department of electricity, now they go to Germany." And again, "Germany is rapidly moving toward industrial supremacy in Europe. One of the most potent factors in this notable advance is the perfected alliance between science and commerce existing in Germany. Science has come to be regarded there as a commercial factor. If England is losing her supremacy in manufactures and in commerce, as many claim, it is because of English conservatism, and the failure to utilise to the fullest extent the lessons taught by science."

Britain, of course, is the country in which such an institution ought to have been established more than half a century ago. We are now compelled to imitate it ; but the new institution which, before long, may be instituted is on such a microscopic scale that its utility in the present struggle is more than doubtful.

The next conclusion the appeal to the law provides us with is that the improved scientific instruction of NO. I 627 , voL. 63 ] those engaged in Industry is not the only line along which our defences must be strengthened. The scientific spirit must be applied as generally in England as elsewhere.

The increasing complexity of industrial and national life requires a closer adjustment of means to ends, and this can only be attained by those who have had education on a scientific basis, and have therefore acquired the scientific habit. In this way only can we lift the whole standard of our national life to a higher plane, and weld the various national activities together.

We must have a profound change of front on the part of the Ministry and the personnel of Government departments, only very few of whom have had any scientific education and who at present regard all scientific questions with apathy, on the ground, perhaps, that in their opinion the $\mathrm{N}$ ation has no direct concern with them. This fecling may be strengthened by the fact that at present, while the laws of the realm are well looked after by the most hig hly paid servants of the State, the laws of Nature are left without anybody to form a court of appeal in difficult questions. It is true that to fill this gap our men of science are always ready, when called upon, to spend time and energy on affurding, gratis, to the Government advice on any questions which may be submitted to them; but because this advice costs nothing its value is, perhaps, estimated by what it costs.

Our rulers must recognise that, in virtue of the law to which reference has been made, it will not do to confine their energies and the national expenditure, so largely as they do now, to matters relating to the Navy and Army, the functions of which are to protect our world-wide Empire at present well worth conquering, our industries, and our argosies on every sea-products, all of them, of our old scientific and therefore commercial supremacy.

Several obvious corollaries from the law in question indiçate very clearly the proper course to pursue, in our own case to retain our position, in the case of our competitors to improve their own in relation to us, and therefore at our expense. There are many signs that our competitors, at all events, have faced this problem and are working on true scientific lines; of this the heavy subsidy of the German mercantile marine may be given as one instance out of many, and here, indeed, we are brought face to face with the consideration that the scientific outlook should really be as important to those in charge of the Nation's future well-being as that concerned with international politics.

If the other nations, by their scientific activity, increase their commerce and therefore their commercial fleets, their national fleets must be increased also. Our present policy with regard to our fleet is well established, so that we are committed to its continuous and well-defined increase, while it seems to be the duty of no Government department to look after the scientific advances which are the only bases of the commerce which is to provide for the constantly increasing expenditure. So that if, in the future, a constantly reduced commerce and commercial marine, and therefore reduced 
national income, are in store for us, we shall have, because of this condition of things, to face a constantly increased expenditure upon our flect.

These considerations are only typical of others which are well worth considering at the present juncture by men possessing the scientific spirit. What is the best way of utilising the combined forces of the Empire, in times of peace, under the present conditions? It is clear that no merely sentimental bonds will be sufficient. We may add that peaceful conflicts between industrial peoples are not alone in question.

With regard to preparation for war, history has already taught us much. Of two competitors, if one be fully armed both for offence and defence, and the other is not, there is no doubt as to what will happen. That nation will be the best off which utilises the greatest number of its citizens both for war and peace. A large standing army in times of peace is a clear indication that the scientific spirit has not been sufficiently applied to the problem, and it is to be hoped that now the future of the Nation is being discussed, the attempts to put our house in order will be made on scientific lines.

EDITOR.

\section{RECENT ADVANCES IN THE CHEMISTRY OF THE PROTEIDS.}

Chemie der Eiweisskörper. Von Dr. Otto Cohnheim. Pp. $x+3$ I5. (Braunschweig : F. Vieweg und Sohn, 1900.)

SINCE the publication of Drechsel's article on proteids $D$ in Ladenburg's Encyclopiedia, no complete account of the chemistry of the proteids has appeared. The accounts given in the best known text-books of physiological chemistry are necessarily brief and incomplete. Dr. Cohnheim's book is therefore a very welcome addition to the literature of physiological chemistry, giving, as it does, a detailed account of the present state of knowledge with regard to the proteids.

The book is divided into a general and a special part. The first deals with the physical and chemical properties of the proteids, then with the products of their decomposition, and finally discusses their structure and classification. In the second part, the characteristics of the different forms of proteids are considered in detail.

In reviewing the book as a whole, it is impossible to do more than emphasise those features in which it shows a distinct advance as compared with its predecessors.

The chief characteristics which distinguish the proteids as a sharply limited class of organic compounds are the following. They contain the elements carbon, hydrogen, oxygen, nitrngen and, as a rule, sulphur in fairly constant proportions, and although their constitution is as yet unknown, the similarity in their chemical behaviour is so great that they may all be regarded as having a common chemical structure. Provisionally they may be divided into three groups, the native simple proteids, the compound proteids - in which a simple proteid is united to some other organic body-and the earlier decomposition products which still retain, in large measure, the chemical properties of the proteids from which they NO. 1627 , voL. 63$]$ have been derived. The compound proteids may contain, in addition to the elements already mentioned, phosphorus and iron.

Their properties may be divided into physical and chemical. Taking the former first, the author selects, as their most characteristic property, the tendency of all native proteids to pass readily out of solution in the form of a more or less permanently insoluble precipitate or coagulum.

Means otherwise chemically indifferent, such as mechanical agitation of their solutions, contact with porous substances, or evaporation of part of the water of solution, result in the separation of a flocculent precipitate, which, on microscopic examination, is found to consist of minute particles tending to cohere so as to form membranes or threads of coagulated proteid. It is this property of proteids which explains their indiffusibility and the difficulty with which they undergo crystallisation.

Chief amongst the physical agents which produce this change is heat. To the subject of coagulation by heat a special chapter is therefore devoted. In the presence of a fixed quantity of neutral salt of the metals of the alkalies, and a very faint acid reaction, the temperature of coagulation is fairly constant for each native proteid, and has proved of considerable value in their separation and classification. A variation in the quantity or nature of the salt used alters the temperature of coagulation of any given proteid. Further, the proteid that separates out from a faintly acid solution carries with it some of the acid, so that the solution after coagulation is found to be less acid than before, or may even be neutral. The latter fact renders the coagulation of proteids by heat specially liable to fallacy as a method for their separation. The part played by the neutral salt in heat coagulation is still doubtful. Most observers have found that proteids, in solutions freed as far as possible from salts by dialysis, do not coagulate on heating; but the addition of a small quantity of neutral salt to the previously heated solution results in the separation of a coagulum. Cohnheim, therefore, regards coagulation by heat as invariably associated with the formation of an acid albumin insoluble in salt solution; but soluble in the least excess of the acid used. The evidence, however, on the influence exerted by neutral salts on the temperature of coagulation is conflicting. 'There is evidence that, in some cases, a proteid solution, freed as far as possible from salts by means of dialysis, coagulates at a lower temperature than when a small quantity of neutral salt is present. By means of dialysis alone it has not, as yet, been found possible to obtain a native proteid free from ash, so that the influence of heat upon a native proteid solution free from mineral matter has not yet been studied.

The next section of the book deals with the methods used for salting out proteids, and contains a complete account of the relative value of various salts as precipitants. Of all salts of the metals of the alkalies and alkaline earths, ammonium sulphate has the greatest precipitating power. Saturation with it precipitates all the native proteids from solution, and, with the exception of peptone, all the products of peptic or tryptic digestion still retaining proteid characters. Its precipitating power is increased by the addition of dilute acids, and, in the 